\title{
Descrição do léxico por meio de nomes de operações policiais a partir de um corpus de notícias*
}

\section{Description of the lexicon through the names of police operations based on a corpus composed by news}

\author{
Guilherme Fromm ${ }^{1}$ \\ Candice Guarato Santos ${ }^{2}$
}

\begin{abstract}
Recebido em: 14/05/2021
Aprovado em: 01/07/2021

Publicado em: 30/07/2021
\end{abstract}

Resumo: Este trabalho tem o objetivo de mostrar os principais resultados de uma pesquisa lexical sobre nomes de operações policiais por meio de um corpus de notícias. O foco do presente estudo é analisar as informações sobre as origens dos nomes das operações apresentadas pelas notícias. Esses dados foram identificados com o auxílio de um software de análise lexical. No corpus, foram identificados 31 nomes de operações inspiradas em nomes de lugares, 28 nomes que remetem a estrangeirismos e 20 nomes que fazem alusão às Mitologias. As análises mostraram que: há operações que recebem o nome do local de onde foram realizadas, especialmente de nomes de bairros, e outras que são nomeadas com topônimos por metáfora; há o uso estrangeirismos da língua inglesa, principalmente nos casos de combate a crimes cibernéticos, e do latim; no caso das mitologias, há a preferência pela mitologia grega e há a relação de metáfora entre o nome e o elemento mitológico. As perspectivas teóricas foram embasadas na Lexicologia e na Onomástica. A metodologia foi guiada pela Linguística de Corpus.

Palavras-chave: Lexicologia; Onomástica; Linguística de Corpus; Operações policiais.

\begin{abstract}
The present paper aims to show the main results of a lexical research on names of police operations through a corpus of news. The focus of the present study is to analyze the information about the origins of the names of the operations presented by the news. These data were identified with the aid of a lexical analysis software. In the corpus, 31 names of police operations were inspired by place names, 28 names refer to loanwords and 20 names refer to Mythologies. The analyses showed that: there are operations that are named based on the place where they were performed, especially neighborhood names, and others that are named with toponyms by metaphor; there is the use of loanwords from the English language, mainly in the cases of combating cybercrime, and of Latin; in the case of mythologies, there is a preference for Greek mythology and there is a metaphor connection between the name and the mythological element. Theoretical perspectives were based on Lexicology and Onomastics. The methodology was guided by Corpus Linguistics.
\end{abstract}

Keywords: Lexicology; Onomastics; Corpus Linguistics; Police operations.

* O presente trabalho foi realizado com apoio da Coordenação de Aperfeiçoamento de Pessoal de Nível Superior - Brasil (CAPES) - Código de Financiamento 001.

1. Doutorado em Estudos Linguísticos e Literários em Inglês pela Universidade de São Paulo. Professor Associado 2 da Universidade Federal de Uberlândia. ORCID: 0000-0001-5654-0135. E-mail: guifromm@ufu.br.

2. Letras - Português e Inglês (Licenciatura). Mestrado em Estudos Linguísticos. Doutoranda no PPGEL/UFU. ORCID: 0000-0001-5957-1842. E-mail: candiceguaratos@gmail.com.

Agradecimentos 
FROMM, G.; SANTOS, C.G.

\section{INTRODUÇÃO}

Em nossa pesquisa (SANTOS, 2017), que se propôs a investigar a inventividade presente na forma em que as forças policiais nomearam suas ações, constatamos certos padrões no léxico utilizado para batizar as operações policiais. Tal trabalho foi fundamentado principalmente nos conceitos da Lexicologia e a metodologia foi baseada na Linguística de Corpus.

O corpus composto por notícias de jornais mineiros revelou não apenas os nomes das operações, mas também informações sobre o que motivou o emprego daquela denominação. Diante desse tipo de contribuição que o corpus ofereceu à nossas análises, no presente trabalho focaremos nos casos em que o próprio corpus de pesquisa apresentou explicações sobre a origem do nome da operação.

As palavras utilizadas para nomear as operações policiais, pessoas, lugares, objetos e outros elementos carregam marcas da cultura de seus falantes. Conforme Paula, Almeida e Rezende (2016), o processo de denominação engloba a parte cultural da língua, pois $\mathrm{o}$ ato de nomear um objeto valida a sua existência no meio social. As autoras complementam que "o léxico é dos subsistemas da língua o que melhor reflete os traços culturais de uma comunidade linguística" (PAULA, ALMEIDA e REZENDE, 2016, p. 13).

Este estudo é relevante porque, como o léxico consiste em um inventário aberto para mudanças, os nomes em questão, que batizam as operações policiais, também contribuem para o enriquecimento do inventário da nossa língua, visto que são palavras que já existem, mas que foram empregadas em novos contextos. A Linguística de Corpus como abordagem propicia o exame de grandes quantidades de informações linguísticas sobre o léxico da língua.

Outro fator importante é que os nomes das operações atraem a atenção do falante sobre a própria língua ao se interessar sobre qual seria a motivação do nome da ação quando ela é noticiada.

Este artigo está dividido nas cinco seções: Introdução, em que o tema central é contextualizado; Fundamentação teórica, que aborda os conceitos sobre léxico, Onomástica e Linguística de Corpus; Metodologia, que descreve o processo de compilação do corpus; Análises dos dados, que contém o estudo das informações coletadas; Considerações finais, com as reflexões sobre este trabalho. A seguir, discorreremos sobre as questões teóricas que embasaram este estudo. 
FROMM, G.; SANTOS, C.G.

\section{FUNDAMENTAÇÃO TEÓRICA}

Esta seção está subdividida em três subseções: Léxico, cultura e nome, Onomástica e suas ramificações e Linguística de Corpus e o programa WordSmith Tools. Antes de versar sobre os nomes, abordamos, na próxima subseção, a relação entre léxico, cultura e nome.

\section{Léxico, cultura e nome}

O léxico é composto por todas as lexias, ou seja, as palavras de uma língua de uma comunidade de falantes. Visto que a sociedade continuamente passa por transformações, essas mudanças precisam ser nomeadas e classificadas, consequentemente, o léxico também passa por alterações.

De acordo com Alves (2007), o léxico de uma língua é expandido por meio do seu próprio acervo existente e a partir do contato com outras comunidades linguísticas. Um dos resultados desse encontro de culturas é o uso de estrangeirismos, que para um linguista, é um tipo de neologismo por empréstimo.

Bem como os neologismos, a metáfora também contribui na produtividade do léxico, uma vez que, nesse processo, o sentido de uma palavra passa por alterações. Segundo Barbosa (2016), a aproximação dos traços semânticos de duas palavras origina o sentido metafórico, que não substituirá o sentido original, porém manterá parte de suas características, podendo gerar novos sentidos.

Uma vez que o léxico tem fortes ligações com a cultura, Martins (2017, p. 40) defende que "os estudos lexicais não podem ignorar as peculiaridades culturais que impulsionaram a ocorrência dos fenômenos responsáveis à evolução do léxico". A autora complementa que o pesquisador não pode ignorar o universo que engloba o léxico ao seguir uma abordagem somente objetiva.

Quanto à origem do léxico de uma língua natural, Biderman (1987) explica que esse processo é consequência de uma forma de registrar os elementos que cercam os falantes. Tal registro, para a lexicóloga, é uma forma de organizar o mundo que cerca o falante de uma dada comunidade linguística:

O léxico de uma língua natural constitui uma forma de registrar o conhecimento do universo. Ao dar nomes aos objetos, o homem os classifica simultaneamente. Assim, a nomeação da realidade pode ser considerada como a etapa primeira no percurso científico do espírito humano de conhecimento do universo. Ao reunir os objetos em grupos, identificando semelhanças $e$, inversamente, discriminando os traços distintivos que individualizam esses objetos em entidades diferentes, 0 homem foi estruturando o mundo que o cerca, rotulando essas entidades 
FROMM, G.; SANTOS, C.G.

discriminadas. Foi esse processo de nomeação que gerou o léxico das línguas naturais (BIDERMAN, 1987, p. 81).

Nessa afirmação, podemos observar que a ação de nomear estabelece ligações entre o ser humano e a realidade, além de estruturar o léxico. Segundo Paula, Almeida e Rezende (2016), o léxico consiste no subsistema mais dinâmico e, por isso, ele pode ser estudado conforme diversas perspectivas da linguagem.

No campo da Linguística, há várias perspectivas que estudam o léxico sob diferentes ângulos, entre os quais podemos citar a Lexicologia, a Lexicografia, a Terminologia, a Terminografia e a Onomástica. Sumariamente, a Lexicologia tem a palavra como objeto de estudo, a Lexicografia trabalha com a parte prática dessa primeira disciplina, por exemplo, a produção de obras de referência, como os dicionários e bases de dados lexicais.

A Terminologia, por outro lado, se atém aos termos, ou seja, palavras típicas de uma área de especialidade. Aliada à Terminologia, a Terminografia se dedica à elaboração de obras de consulta sobre os termos. Zavaglia et al. (2010) expõem as diferenças entre a Lexicologia e a Terminologia e alertam que os limites entre essas duas áreas não são bem definidos no discurso:

A Terminologia e a Lexicologia, apesar de serem ciências que lidam com o universo da palavra, possuem materiais e métodos de caracterização e percursos de investigação diferentes: grosso modo, a Lexicologia concentra-se no estudo do chamado léxico geral, em que se incluem também termos, e a Terminologia, no estudo do chamado léxico especializado. Essa fronteira, porém, não é nítida no discurso, em que as palavras podem trafegar, dependendo do tipo de texto, de um domínio a outro (ZAVAGLIA et al., 2010, p. 19).

Como se pode observar nessa afirmação, o objeto de estudo da Lexicologia é mais amplo que o da Terminologia, pois a primeira disciplina lida com todas as palavras do acervo de uma língua, enquanto a segunda se restringe aos termos de uma área de especialidade.

Além da Lexicologia, da Lexicografia, da Terminologia e da Terminografia, a Onomástica também integra as ciências do léxico. Entretanto, esta disciplina trabalha com os nomes próprios. Paula, Almeida e Rezende (2016) explicam que a unidade lexical também pode ser chamada de nome, pois a palavra nomeia os conhecimentos dos membros de uma comunidade linguística:

Assim, o léxico das línguas naturais engloba todo o conhecimento que todos os falantes de uma língua natural têm, rotulado sob a forma de nomes que podem ser chamados também de unidades ou palavras lexicais. O nome, além de designar, traz consigo uma história, pois sempre existe uma motivação que de certa forma justifica a opção de uma

Revista do SELL, Uberaba/MG (online) - V. 10 n. 1, p.56-75, jan. /jun. - 2021. 
comunidade linguística por determinado nome. Este pode remeter ainda a diversas realidades, pois um nome/signo pode ter uma significação geral e uma específica, a depender de diversos fatores, como o momento histórico ou o contexto social em que for utilizado, constituindo um vocabulário correspondente a uma situação peculiar (PAULA, ALMEIDA; REZENDE, 2016, p. 13).

A Onomástica também oferece suporte teórico para os estudos que envolvem análises sobre a origem, a motivação e as relações dos nomes com fatores culturais, mas, neste caso, ela se restringe à investigação dos nomes próprios. Para detalhar a questão das denominações, discutiremos, a seguir, aspectos relativos à Onomástica.

\section{Onomástica e suas ramificações}

Atrelada aos estudos do léxico, a Onomástica visa tecer estudos sobre um tipo característico de lexia, os nomes próprios. Quando se objetiva analisar nomes, apelidos e sobrenomes de pessoas, a subárea responsável é a Antroponímia, enquanto o propósito da Toponímia é a análise de nomes próprios de lugares. Melo (2017) relaciona a Onomástica com a Linguística ao apresentar as ramificações dessa disciplina dos nomes:

Considerando a Linguística como a teoria da linguagem humana, a Onomástica se integra aos estudos linguísticos, particularmente às pesquisas do léxico, ocupando-se em investigar os nomes próprios em geral e os sistemas de nomeação. Neste aspecto, ela corresponde a uma disciplina maior que apresenta duas áreas correlatas: a Toponímia, que possui como eixo central de seus estudos o nome próprio de lugar (topônimo), e a Antroponímia, que se ocupa dos estudos do nome próprio de pessoas (antropônimo) (MELO, 2017, p. 246).

Sobre os antropônimos, ou seja, nomes próprios de pessoas, Zamariano (2012, p. 366) explica que os "apelidos ou nomes foram a forma encontrada para distinguir as pessoas da família e da comunidade, facilitando, assim, a identificação de cada um de seus membros". Quanto à origem do uso de antropônimos, Carvalhinhos (2007) explana que, tempos atrás, a denominação que a pessoa recebia era motivada por suas características. Entretanto, segundo a autora, devido à dinamicidade da língua, o sentido original do nome foi se esvaziando, tornando-se opaco e impedindo que o seu significado fosse reconhecido.

No caso dos topônimos, isto é, os nomes próprios de lugares, o apagamento do significado inicial do nome pode não acontecer, assim, as particularidades do lugar batizado, além de motivarem a nomeação, também podem ser identificadas no momento em que o seu nome é pronunciado pelos falantes da comunidade linguística, conforme Seabra (2006): 
Os nomes de lugares designam de uma maneira única um espaço físico que corresponde a um conjunto de descrições ou, se quisermos, que é identificável por um determinado conjunto de propriedades que só a ele dizem respeito. Na maioria das vezes, essa nomeação se dá quando um lugar é "batizado" por uma pessoa ou por um grupo no início de seu povoamento e esse batismo passa a fazer parte da cadeia de acontecimentos que levou o denominador a associar o espaço físico ao nome, transmitindo-o, em seguida, aos membros de uma comunidade linguística. Nesse processo, quando se consegue preservar o sentido, preserva-se a informação sobre o lugar (SEABRA, 2006, p. 1956).

Apesar de ambos se configurarem igualmente como nomes, os antropônimos e os topônimos exercem papéis diferentes, pois "enquanto que os topônimos definem e precisam os contornos de qualquer paisagem terrestre, os antropônimos se referem à distinção dos indivíduos entre si" (ZAMARIANO, 2012, p. 366). A autora complementa que os dois tipos de nomeação são uma forma de registrar o cotidiano.

A seguir, apresentaremos aspectos que envolvem a Linguística de Corpus e o programa de análise lexical WordSmith Tools, versão 6.

\section{Linguística de Corpus e o programa WordSmith Tools}

A Linguística de Corpus (doravante LC), adotada como abordagem, busca descrever e analisar dados linguísticos por meio de uma quantidade extensa de textos armazenados em formato eletrônico. Nas palavras de Fromm (2003), corpus, na Linguística, significa uma coleção de textos com um objetivo específico de estudo. Segundo o autor, um corpus é diferente de uma coletânea ou de uma antologia, que agrupam obras ou trechos de obras com um objetivo didático ou comercial.

Devido à dinamicidade dos recursos computacionais e à possibilidade de se investigar muitos textos compilados e agrupados em corpus ou em corpora (plural de corpus), Dayrell (2005) destaca a importância da pareceria entre a LC e os estudos na área da Linguística:

Corpora representam, portanto, a disponibilidade de um grande volume de dados empíricos, e a incorporação de ferramentas computacionais para análise desses textos revolucionou o estudo da linguagem. Assim sendo, a Linguística de Corpus, ramo da Linguística que utiliza corpora para o estudo da linguagem, abriu novas perspectivas e a possibilidade de explorar e investigar, em grande escala, regularidades e padrões inerentes à linguagem (DAYRELL, 2005, p. 87).

A aplicação da LC como metodologia apresenta vários benefícios. Entre as vantagens, há o amparo da tecnologia tanto no armazenamento de textos, quanto exploração dos corpora e a análise de informações que não são resultado apenas de introspecção, mas sim de dados reais:

Revista do SELL, Uberaba/MG (online) - V. 10 n. 1, p.56-75, jan. /jun. - 2021. 
A Linguística de Corpus trabalha dentro de um quadro conceitual formado por uma abordagem empirista e uma visão da linguagem como sistema probabilístico; encaixa-se no que pode ser chamado de Linguística Empírica. $\mathrm{Na}$ linguística, empírico significa primazia aos dados provenientes da observação da linguagem, em geral reunidos sob a forma de um corpus. Essa posição empírica contrapõe-se a uma visão racionalista da linguagem, segundo a qual, em linhas gerais, o conhecimento provém de princípios, estabelecidos a priori (BERBER SARDINHA, 2004, p. 30).

O programa de análise lexical escolhido para a exploração do corpus de pesquisa foi o WordSmith Tools (SCOTT, 2012), versão 6. Conforme Berber Sardinha (1999, p. 1), esse software é composto por uma "suíte" com programas "que compreendem o préprocessamento, a organização de dados, e a análise propriamente dita de corpora ou textos isolados".

Três ferramentas básicas, WordList, KeyWords e Concord, integram o WordSmith Tools. A WordList, ou lista de palavras disponibiliza uma listagem com todas as palavras do corpus, além de apresentar o número total de palavras do corpus, os tokens, e a quantidade de palavras diferentes, os types. A KeyWords List, ou lista de palavras-chave, consiste no resultado de uma análise contrastiva entre o corpus de estudo e o um corpus de referência.

Com o auxílio do Concord é possível buscar por uma palavra específica no corpus, também chamada de nódulo. Tal ferramenta cria uma lista em que todas as ocorrências dessa palavra de busca aparecem em linhas de concordância. Nessas linhas podem-se visualizar padrões lexicais, pois o nódulo aparece acompanhado de seu contexto. De forma resumida, o WordSmith Tools permite trabalhar com dados numéricos e com a realização de estudos qualitativos em grandes quantidades de textos, visto que a frequência pode auxiliar na identificação de certos padrões na língua.

Após a apresentação de conceitos relativos à Linguística de Corpus e do software WordSmith Tools, prosseguimos para a metodologia de pesquisa na próxima seção.

\section{METODOLOGIA}

Dividimos esta seção em três partes: na primeira, explicamos como o corpus de estudo foi escolhido; na segunda subseção mostramos como o corpus foi compilado; na terceira parte demonstramos como foi o processo de organização dos campos semânticos para a identificação de padrões nos nomes. 
FROMM, G.; SANTOS, C.G.

\section{Escolha do corpus}

Como não foi possível compilar a mesma quantidade de notícias das regiões Norte, Nordeste, Centro-Oeste, Sul e Sudeste, devido à quantidade desigual de jornais por região, decidimos compilar as notícias de jornais de apenas um estado do Brasil, ou seja, das maiores cidades de Minas Gerais.

Para o levantamento dos jornais, identificamos as dez maiores cidades, em número populacional, do estado de Minas Gerais, que são: Belo Horizonte, Uberlândia, Contagem, Juiz de Fora, Betim, Montes Claros, Ribeirão das Neves, Uberaba, Governador Valadares e Ipatinga. Partimos da hipótese de que os municípios com maior população possuem os maiores jornais que, em consequência, atingem maior número de falantes da língua.

Depois, baseamo-nos na lista de registro dos jornais mineiros, apresentada por Rezende (2011), para a investigação dos jornais das cidades citadas anteriormente. Os critérios de escolha das publicações foram: o jornal estar em circulação, no momento em que a coleta das notícias estava em processo; dispor de grande quantidade de notícias sobre operações policiais; disponibilizar suas notícias para não assinantes e ter site, para que os processos de armazenamento dos textos e de análises, por meio do programa, fossem mais ágeis.

Os jornais selecionados foram: Estado de Minas, O Tempo, Aqui e Super Notícia, de Belo Horizonte; Correio de Uberlândia e Gazeta de Uberlândia, da cidade de Uberlândia; Folha de Contagem, do município de Contagem; Tribuna de Minas, de Juiz de Fora; Jornal da Manhã e Jornal de Uberaba, da cidade de Uberaba e o Diário Popular, do município de Ipatinga.

Os jornais das cidades de Betim, Montes Claros e Ribeirão das Neves não foram selecionados porque suas publicações, que estavam na listagem, não atenderam aos nossos critérios para a compilação do corpus.

Na próxima subseção, será detalhado como ocorreu o processo de coleta das notícias dos jornais escolhidos para a pesquisa.

\section{Compilação do corpus}

Realizamos as buscas pelas notícias dos jornais por meio do Google. Para tal procedimento, digitamos no espaço "pesquise no Google ou digite um URL" o seguinte comando: "operação site:" mais o link do site do jornal do qual pretendíamos coletar a notícia. Esse recurso possibilitou acessar de forma mais dinâmica os conteúdos das 
FROMM, G.; SANTOS, C.G.

publicações selecionadas e permitiu avaliar se a notícia realmente informava sobre uma operação policial.

As notícias que atenderam a esse critério foram salvas no formato somente texto (txt) e na codificação unicode, de acordo com a exigência do software WordSmith Tools (SCOTT, 2012). Para identificar o texto, foi inserido um rodapé, entre chaves angulares, informando a data da coleta e a fonte da notícia.

No total, foram 1.310 notícias compiladas. Com base na tipologia de corpus de Teixeira (2008), o nosso corpus de estudo é: monolíngue; contemporâneo; escrito; foi compilado para fins de estudo; os textos foram produzidos por nativos falantes da língua portuguesa; apresenta 425.722 tokens e 19.832 types; possui cabeçalhos, mas não é etiquetado.

\section{Organização dos campos semânticos}

Com o intuito de identificar os nomes das operações presentes no corpus de estudo, utilizamos a ferramenta Concord. Inserimos a palavra de busca "operação" que resultou em 4.113 ocorrências, ou seja, linhas de concordância por meio das quais foi possível identificar 365 designações.

Parte dessas denominações não estava acompanhada da palavra "operação", assim foi necessário ir além da linha de concordância, isto é, acessar a notícia completa por meio do próprio programa para detectar o nome.

Categorizamos as denominações identificadas em campos nos quais os nomes compartilham pelo menos um traço semântico. O processo de classificação em campos semânticos foi amparado nas informações apresentadas pelo corpus de estudo, em outras palavras, nas explicações que as notícias apresentavam sobre a motivação do nome. Outras fontes de consulta foram os dicionários Aulete Digital (2007) e Michaelis (2015), nas versões on-line. Porém, quando isso não foi possível, como no caso de alguns nomes mitológicos que não foram dicionarizados, realizamos buscas por meio do Google.

Foram elaborados 38 campos semânticos, cada um com pelo menos duas designações de operações policiais, além do grupo dos casos indefinidos, composto por denominações que não se encaixaram nos outros grupos ou que integravam campos com menos de duas ocorrências. Os quatro campos semânticos com maiores ocorrências foram Lugar, com 31 nomes, Estrangeirismos, com 28 nomes, Mitologias, com 20 nomes e Datas, também com 20 nomes.

$\mathrm{Na}$ próxima seção, apresentamos as análises dos três primeiros campos semânticos (em termos de quantidade de operações em cada um) guiadas pelos trechos, 
FROMM, G.; SANTOS, C.G.

identificados pelo Concord, em que a própria notícia explica a motivação do nome escolhido ou revela indícios sobre esse tipo de informação.

\section{Análises dos dados}

Conforme foi explicado na Introdução, exibiremos as designações identificadas e classificadas nos três grandes grupos Lugar, Estrangeirismos e Mitologias, mas focaremos as análises nos casos em que o próprio corpus apresentou informações sobre a motivação dos nomes.

Apesar de o campo semântico Datas conter 20 casos, assim como o das Mitologias, ele não será analisado neste trabalho, devido ao espaço neste artigo.

\section{Referência a nomes de Lugares}

Neste estudo, verificamos a alta frequência de nomes de operações motivados por topônimos, ou seja, nomes de espaços físicos. Do total de 31 denominações inspiradas em topônimos, identificamos 13 nomes que foram influenciados pelo local onde a ação foi realizada, a saber, BH Segura, Cachoeira, Carajás, Cerco ao Vera Cruz, Cidade de Deus, Custo Brasil, Fronteira, Limpeza de Delta, Nova Felicidade, Minas Segura, Primavera, São José e Recanto das Cigarras.

A maioria desses casos remete a nomes de bairros, pois, Carajás (01) é um bairro de Contagem; Cerco ao Vera Cruz (02), Nova Felicidade (03) e São José (04) remetem aos bairros Vera Cruz, Conjunto Felicidade e São José, de Belo Horizonte; Primavera (05) é uma alusão ao bairro da cidade mineira Timóteo. Pode-se observar isso por meio dos seguintes trechos, retirados do próprio corpus de estudo, das notícias sobre essas ações:

(01) Durante a operação "Carajás", oito pessoas foram presas em Contagem [...] Os oito detidos são de Contagem, dos bairros Nacional, Xangri-lá e Carajás, e são conhecidos e amigos de longa data (O Tempo/2015).

(02) Três pessoas foram presas e cerca de 40 quilos de crack apreendidos na tarde desta quinta-feira durante a operação "Cerco ao vera Cruz" realizada de combater o tráfico de drogas na Região Leste de Belo Horizonte (Estado de Minas/2015).

(03) A justificativa da polícia para realizar a operação, batizada de Nova Felicidade [...] é que as regiões têm os mais altos índices de homicídios relacionados ao tráfico de drogas na Grande BH. A maior parte das detenções aconteceu nos bairros Conjunto Felicidade e Primeiro de Maio, na região Norte da capital. Foram oito pessoas detidas (O Tempo/2010).

(04) Nove são detidos em operação policial no bairro São José, na Pampulha [...] Operação São José (O Tempo). 
FROMM, G.; SANTOS, C.G.

(05) Um homem que se passava por falso policial civil foi preso na manhã desta sextafeira (18), no bairro Primavera [...] Ainda na manhã desta sexta-feira, a PC deflagrou a operação "Primavera" (Diário Popular/2015).

Em seguida, está o conjunto de nomes motivados pela cidade e estado em que a operação ocorreu, visto que Fronteira, Limpeza de Delta e BH Segura aludem às cidades mineiras de Fronteira, Delta e Belo Horizonte, e Minas Segura faz alusão ao estado de Minas Gerais. No corpus, encontramos a explicação somente para Fronteira (06):

(06) As Polícias Rodoviárias Federal e Estadual, Polícia Civil e Polícia Militar realizam a Operação Fronteira [...] os policiais se empenharam em Sacramento, Ponte de Delta, Planura, Fronteira (Jornal de Uberaba/2013).

Em menor frequência, identificamos um nome inspirado em um país e outro motivado por um distrito. A operação Custo Brasil remete ao país Brasil e a operação Cachoeira (07) faz alusão ao distrito Cachoeira do Vale, da cidade de Timóteo:

(07) Foram condenados 13 das 17 pessoas indiciadas pela Polícia Civil de Timóteo, por tráfico de drogas, associação ao tráfico, corrupção de menores e falsificação de documentos. Os envolvidos fizeram parte das investigações denominada Operação Cachoeira. O inquérito policial, um calhamaço de aproximadamente 1.500 páginas, foi remetido ao Ministério Público, e traz em detalhes um forte esquema de tráfico de drogas no distrito de Cachoeira do Vale (Diário Popular/2014).

Um parque também foi inspiração no processo de nomear uma ação da polícia. $O$ parque Recanto das Cigarras, situado no campus da Universidade Federal de Viçosa (UFV), nomeou a ação homônima como se pode ver em (08):

(08) A Polícia Federal deflagrou ontem (20) a Operação Recanto das Cigarras para investigar desvios de recursos da Universidade Federal de Viçosa (UFV) (Diário Popular/2016).

Os outros 20 topônimos foram motivados por nomes lugares em que a operação não foi realizada. Em tal subgrupo de topônimos, detectamos a tendência de nomear as ações com base em cidades, a saber, as operações Alexandria, Calicute, Medellin 1/ Medellin 2 e Porto Victoria, que foram nomeadas a partir das cidades de Alexandria, situada no Egito, Calicute, localizada na Índia, Medellin, da Colômbia, e Porto Victoria, um município do estado do Paraná.

Os nomes Afeganistão, Expresso Canadá e Samoa foram inspirados nos países Afeganistão, Canadá e Samoa, um país da Oceania. Sudeste S./A e Triângulo das Bermudas foram motivados pelos nomes das regiões Sudeste, região que compreende os 
FROMM, G.; SANTOS, C.G.

estados de São Paulo, Rio de Janeiro, Minas Gerais e Espírito Santo, e Triângulo das Bermudas, área entre ilhas que abrange três ilhas no Oceano Atlântico.

Os acidentes geográficos Andes e Rio Grande nomearam duas ações policiais. As operações Caatinga e Deserto fazem alusão aos biomas de mesmo nome. As ilhas Alcatraz, onde é localizada uma prisão federal americana, e Saint Michel, da França, batizaram as operações homônimas.

As operações Faixa de Gaza, Oriente e Dedo de Deus foram intituladas, respectivamente, pelo território palestino de mesmo nome, pela posição geográfica oriente, e pelo pico chamado Dedo de Deus, localizado no Rio de Janeiro.

Concluindo este grupo de topônimos, o sítio arqueológico Lapa da Pedra influenciou o nome da investigação sobre um grupo de criminosos que fraudava o INSS (Instituto Nacional do Seguro Social), conforme explica o trecho (09) do corpus de estudo:

(09) O nome da operação, Lapa da Pedra, faz referência a um sítio arqueológico localizado em Formosa/GO, cujas marcas deixadas pelos paleolíndios possibilitaram sua descoberta, o mesmo tendo ocorrido com as marcas deixadas pela organização criminosa (Estado de Minas/2015).

Quanto ao primeiro grupo de topônimos, em que a atividade policial recebeu o nome do local onde ela foi realizada, observamos a preferência por nomes de bairros. Esse modo de nomear pode ser uma forma de atribuir mais dinamicidade ao momento em que a operação é noticiada, pois logo quando esse tipo de notícia é divulgado, é mais fácil pressupor onde a investigação foi realizada, principalmente para os moradores do bairro em questão.

Tal fato é um exemplo do que discutimos, com base em Seabra (2006), na seção 2.2, pois o apagamento do sentido original da palavra que nomeia um lugar pode não ocorrer e, em consequência, as características que influenciaram na escolha do nome do espaço físico podem ser identificadas quando o seu nome é pronunciado.

Em relação ao segundo agrupamento, no qual o lugar que nomeia ação é diferente do local onde ela foi desenvolvida, identificamos que há uma predisposição em utilizar nomes de cidades. Em alguns casos analisados, foi possível traçar a relação metafórica entre o sentido da palavra que nomeia e as características presentes no desenvolvimento da operação, por exemplo, o trecho (09) em que as marcas dos paleolíndios são comparadas aos sinais deixados pelos criminosos. 
FROMM, G.; SANTOS, C.G.

\section{Referência a estrangeirismos}

Os nomes motivados por estrangeirismos foram o segundo grupo com maior ocorrência. Foram detectados os seguintes 28 estrangeirismos: Abaíte, Aequalis, American Dream, Carpe Diem, Darknet/ Darknet II, Darkode, Deja-Vú, Dirty Net, Firewall, For All, Gemini, Greenfield, Halloween, Hashtag, Hurricane, Initialis, Manducare, Master Cat, Omertà, Papirus, Pecus, Reset, Resgate On-Line, Scriptus, Sieg, Soldner, Narke e Tyrannos.

Dentre esses casos, 14 são empréstimos da língua inglesa, a saber, American Dream, Darknet/Darknet II, Darkode, Dirty Net, Firewall, For All, Gemini, Greenfield, Halloween, Hashtag, Hurricane, Master Cat, Reset e Resgate On-Line. Analisando esses anglicismos, ou seja, palavras oriundas da língua inglesa, percebemos que as palavras que remetem à área da internet foram utilizadas nomear as operações que combateram crimes cibernéticos, como se pode observar nos trechos sobre a Darknet (10), Darkode (11), Dirty Net (12), Firewall (13), Hashtag (14) e Resgate On-Line (15):

(10) A Polícia Federal deflagrou ontem a Operação "Darknet II", com o objetivo de combater rede de distribuição de pornografia infantil na chamada Deep Web (Jornal de Uberaba/2016).

(11) O grupo do qual o mineiro fazia parte agia por meio de um fórum na internet hospedado de forma alternativa e que não pode ser encontrado por meio de buscas convencionais. O site, chamado de Darkode, dá nome também à operação da Polícia Federal (Aqui/2015).

(12) A ação especial foi realizada pelo Grupo Especial de Combate aos Crimes de Ódio e Pornografia Infantil pela Internet, sendo um desdobramento da Operação Dirty Net deflagrada no ano passado no Rio Grande do Sul, quando foram presas 32 pessoas (Aqui/2013).

(13) A Firewall reuniu 25 delegados e 80 agentes de diversas delegacias e contou com apoio de um helicóptero. Ainda de acordo com a polícia, a operação é uma continuidade das investigações da Delegacia de Repressão a Crimes contra a Informática, que começaram em setembro do ano passado (Correio de Uberlândia/2014).

(14) As investigações da Operação Hashtag, de acordo com a PF, começaram em abril com o acompanhamento de redes sociais pela Divisão Antiterrorismo (Correio de Uberlândia/2016).

(15) De acordo com a delegada da PF em Belém (PA) [...] os trabalhos de investigação que culminaram na Operação Resgate On-Line tiveram início a partir da troca de informações obtidas com outras operações, já que essa é a sétima do tipo feita pela PF em 2014, e também do monitoramento de redes sociais (Aqui/2014). 
FROMM, G.; SANTOS, C.G.

O uso de anglicismos na esfera da internet é habitual, consequentemente, tal característica influenciou no modo como essas operações foram designadas, visto que elas investigaram crimes virtuais.

Diferentemente dos outros 13 empréstimos do inglês apresentados nesta subseção, o nome American Dream faz alusão ao desejo de uma condição de vida próspera, conforme a própria notícia explicou por meio do trecho (16):

(16) O nome da operação faz referência ao sonho norte-americano de prosperidade, pois, por meio da fraude milionária, os criminosos levavam a vida com um dinheiro que não Ihes pertencia (Estado de Minas/2015).

As palavras procedentes do latim, ou latinismos, também nomearam operações, mas em menor frequência, ou seja, sete casos: Aequalis, Carpe Diem, Initialis, Manducare, Papirus (papyrus), Pecus, Scriptus e Tyrannos (tyrannus). Apenas a notícia sobre o desenvolvimento da operação Aequalis apresentou a tradução do significado do latinismo que nomeia a ação, conforme o trecho (17):

(17) A operação ganhou o nome de "Aequalis", que significa "igualdade", em latim. O MP informou que, até o momento, não há indícios do envolvimento de autoridades com foro por prerrogativa de função (O Tempo/2016).

Os estrangeirismos do alemão, Sieg e Soldner (söldner), do francês, Deja-Vú (déjà $v u$ ), do italiano, Omertà, do tupi-guarani, Abaíte, e do grego, Narke, também nomearam ações de combate a crimes, porém em menor quantidade. As notícias que informaram sobre as operações Sieg (18), Omertà (19), Abaíte (20) e Narke (21) apresentaram explicações sobre o sentido da palavra estrangeira que nomeia a atividade policial:

(18) De acordo com a Polícia Civil, a execução da Operação Sieg (que significa "vitória", em alemão) resultou na desarticulação de uma das maiores quadrilhas de tráfico de drogas do estado [...] (Aqui/2015).

(19) O nome "Omertà" dado à investigação policial é uma referência a origem italiana do codinome que a construtora usava para fazer referência ao principal investigado da fase ("italiano"), bem como ao voto de silêncio que imperava no Grupo [...] Além disso, remete a postura atual do comando da empresa que se mostra relutante em assumir e descrever os crimes praticados (Correio de Uberlândia/2016).

(20) Na língua tupi-guarani, o termo Abaíte, que dá nome à operação da Polícia Civil, significa "homem mau"; A palavra é o contrário de Abaeté (O Tempo/2009).

(21) Uma pessoa foi presa na manhã de ontem em Belo Horizonte depois que a Polícia Federal (PF) encontrou unidades da toxina botulínica - conhecida como botox - sem rótulo, validade ou nota fiscal. A substância é usada em tratamentos estéticos, entre outros. A operação batizada de Narke, palavra grega que tem relação com 
FROMM, G.; SANTOS, C.G.

narcisismo, foi deflagrada em oito estados: Minas Gerais, São Paulo, Pernambuco, Paraíba, Piauí, Rio Grande do Norte, Alagoas e Sergipe (Aqui/2012).

O emprego de palavras ou expressões provenientes de outra língua, por exemplo, os anglicismos e os latinismos, pode ser uma forma de atribuir status e atrair a atenção da sociedade para o trabalho que as forças policiais vêm desenvolvendo.

\section{Referência a mitologias}

Os universos mitológicos de várias civilizações também exerceram influência no modo de denominar a operações abordadas pelas notícias do corpus. No total foram as seguintes 20 ocorrências: Argos Panoptes, Athos, Era do Trovão, Esfinge, Fênix, Grifo 1/ Grifo 2, Hades, Harpia, Hidra 1/Hidra 2, Ilítia, Janus, Midas, Olimpo, Perséfone, Perseu, Poseidon, Tellus, Têmis, Tisífone e Zeus. A maioria desses nomes provém da mitologia grega, como será mostrado nos próximos parágrafos.

A ação Argos Panoptes investigou pichadores considerados de elite, a Athos pôs fim a um esquema de tráfico de entorpecentes; a Esfinge desmantelou uma quadrilha de fraudes de licitações; a Fênix confiscou medicamentos falsos ou sem aprovação da Agência Nacional de Vigilância Sanitária (Anvisa); a Grifo 1/ Grifo 2 verificou e fiscalizou imóveis de alto padrão e fraudes previdenciárias; a Hades prendeu uma quadrilha que praticava assaltos com extrema violência, tráfico de drogas e assassinato; a Harpia investigou e prendeu acusados de lavagem de dinheiro e tráfico de drogas; a Hidra 1/Hidra 2 repreendeu os crimes de furto, roubo e tráfico de drogas; a Ilítia buscou combater a criminalidade na região do Triângulo Mineiro; a Midas prendeu membros de quadrilhas de roubo a banco; a Olimpo investigou e prendeu suspeitos de uma quadrilha de tráfico de drogas; a Perséfone desmantelou uma quadrilha de roubo de veículos pesados e de tráfico; a Perseu prendeu suspeitos de um grupo criminoso; na Poseidon houve a realização de blitz; a Têmis prendeu integrantes de uma milícia; na Tisífone houve prisões de suspeitos de assaltos e homicídios; a Zeus prendeu suspeitos de tráfico de drogas.

As notícias sobre as operações Argos Panoptes (22), Grifo 1/ Grifo 2 (23), Hades (24), Ilítia (25), Midas (26), Olimpo (27) e Tisífone (28) apresentaram definições e explicações sobre o elemento mitológico aludido pelo nome da ação da polícia, como se pode ver nos respectivos trechos abaixo:

(22) Antes das 8 h, cerca de $80 \%$ da operação "Argos Panoptes" (gigantes da mitologia grega que possuía cem olhos) já havia sido cumprida (O Tempo/2016). 
FROMM, G.; SANTOS, C.G.

(23) Segundo a receita Federal de Minas Gerais, o nome da operação faz alusão ao animal mitológico com corpo de leão e cabeça e asas de águia que simboliza a força e a sabedoria (Correio de Uberlândia/2014).

(24) Na mitologia grega, Hades é apresentado como deus do submundo e da riqueza dos mortos (Estado de Minas/2015).

(25) A operação 'llítia', que teve esse nome por causa da deusa grega llítia, também conhecida como Deusa da Vida Nova, cumpriu ainda 16 mandados de prisão e de busca e apreensão (Estado de Minas/2015).

(26) Uma equipe do Departamento de Operações Especiais (Deoesp) já estava investigando esse tipo de crime na Operação Midas (personagem da mitologia Grega que transformava tudo o que tocava em ouro) (Aqui/2013).

(27) O nome "Olimpo", segundo a Polícia é uma referência à qualidade da droga, considerada pelos suspeitos e pelos usuários a "melhor e mais pura de Betim" (O Tempo/2015).

(28) Noventa policiais civis e militares participaram da operação, que foi chamada de Tisífone em menção à divindade mitológica que persegue e pune autores de assassinatos (Folha de Contagem/ Edição n 482).

Em menor número, identificamos operações cujos nomes fazem alusão à mitologia romana, a saber, a operação Janus, que combateu o tráfico de influência em um banco, e a Tellus, que prendeu pessoas acusadas de roubos. Entretanto, as notícias compiladas não exibiram explicações sobre o que motivou a escolha desses nomes.

No corpus de estudo, encontramos somente um nome inspirado na mitologia nórdica, a operação Era do Trovão. A motivação se baseou não apenas em um deus da mitologia, mas também em uma característica do criminoso investigado pela operação, conforme é explicado no trecho (29):

(29) G. explica que a operação leva o nome de Era do Trovão, numa referência ao chefe da quadrilha [...] que é conhecido como Thor, o deus do trovão, na mitologia nórdica (Diário Popular/2015).

Ao analisar os traços semânticos das explicações dos nomes exibidas pelo corpus e as características que evolveram o desenvolvimento dessas operações notamos que, em alguns casos, há a relação de metáfora, ou seja, nome e investigação compartilham traços semânticos.

Podemos relacionar o traço semântico "gigantes com cem olhos", da operação Argos Panoptes, ao traço "vigiar" da polícia; da Tisífone, o traço "persegue e pune autores de assassinatos" com o ato da polícia de prender criminosos; da Hades, o traço "deus do submundo" com as atitudes fora da lei dos membros da quadrilha; da Midas, o traço "ouro/riqueza" com o banco alvo da operação; da Olimpo, o traço "divino/excelente" com a 
FROMM, G.; SANTOS, C.G.

qualidade da droga apreendida; da Era do Trovão, a relação é estabelecida pelo fato de o apelido do chefe a quadrilha ser igual ao nome do deus Thor do trovão. A aproximação entre os traços semânticos originou um novo sentido metafórico, conforme explicado por Barbosa (2016). Esse novo sentido é a operação. Na próxima seção, apresentamos as considerações finais deste trabalho.

\section{CONSIDERAÇÕES FINAIS}

A análise do corpus de notícias possibilitou a identificação de padrões no modo como os órgãos da polícia batizam as suas operações. Os topônimos, estrangeirismos e elementos mitológicos são particularidades desses padrões.

A investigação a partir das informações sobre a origem dos nomes, que foram apresentadas pelas notícias do corpus, permitiu a visualização de alguns detalhes. Há operações que são batizadas com o mesmo nome do local onde foram realizadas, por exemplo a operação Carajás, um bairro de Contagem, e há operações que recebem o nome de outra localidade por relação de metáfora, exemplificada pela operação Lapa da Pedra, um sítio arqueológico.

Outro detalhe é que o emprego de estrangeirismos da língua inglesa é resultado da influência das investigações que envolveram a área da informática, além do prestígio da língua inglesa. Quanto aos casos dos estrangeirismos do latim, acreditamos que seja uma forma de ornamentar os nomes das operações e, também, devido à proximidade entre a esfera policial e o domínio jurídico, área em que é comum o uso de latinismos.

O uso de palavras que fazem alusão às mitologias, principalmente a grega, foi metafórico, pois há o compartilhamento de sentidos entre o elemento mitológico e a operação. Esse jogo de sentidos com a mitologia cria um nome imponente e atrativo para a população.

Esta pesquisa contribui com um estudo de um recorte do léxico, em que transformações lexicais acontecem de forma dinâmica diante dos membros de nossa comunidade de fala. Os jornais, fonte da coleta do corpus, têm papel fundamental na divulgação dessas mudanças linguísticas.

Este estudo pode colaborar no trabalho com o léxico e com a Onomástica em sala de aula, pois os nomes de operações policiais fazem parte dos noticiários e causam o interesse das pessoas, devido à importância da ação policial e por causa dos nomes curiosos. Santos (2016) propôs um modelo de atividade escolar sobre neologismos em que o aluno, a partir dos traços semânticos presentes na notícia, deve inferir os nomes das operações. 
FROMM, G.; SANTOS, C.G.

Tanto estudar quanto ensinar sobre os nomes é importante porque, conforme Paula, Rezende e Almeida (2016), eles rotulam todo o conhecimento que todos os falantes da língua possuem.

\section{REFERÊNCIAS}

ALVES, M. I. Neologismo: criação lexical. 3 ed. São Paulo: Ática, 2007.

AULETE, F. J. C. Aulete Digital. Rio de Janeiro: Lexikon, 2007. Disponível em: http://www.aulete.com.br/. Acesso em: 22 abr. 2021.

BARBOSA, N. O. A abordagem interacionista da metáfora: um estudo semânticolexical. In: CONGRESSO INTERNACIONAL DE LINGUÍSTICA E FILOLOGIA/ CONGRESSO NACIONAL DE LINGUÍSTICA E FILOLOGIA, 2., 2016, Rio de Janeiro. Anais... Rio de Janeiro: CiFEFiL, 2016. p. 9-29. Disponível em: http://www.filologia.org.br/xx_cnlf/cnlf/cnlf_02/001.pdf. Acesso em: 8 maio 2021.

BERBER SARDINHA, T. Linguística de Corpus. Barueri, SP: Manole, 2004.

BERBER SARDINHA, T. A influência do tamanho do corpus de referência na obtenção de palavras chave. DIRECT Paper 38. LAEL, PUCSP - Pontifícia Universidade Católica de São Paulo, 1999. Disponível em: http://www2.lael.pucsp.br/direct/DirectPapers38.pdf. Acesso em: 15 set. 2019.

BIDERMAN, M. T. C. A estruturação do léxico e a organização do conhecimento. Letras de Hoje, Porto Alegre, v. 22, p. 81-96, dezembro 1987.

CARVALHINHOS, P. D. J. As origens dos nomes das pessoas. Domínios de Lingu@guem, Uberlândia, v. 1, p. 1-18, jan. 2007. Disponível em: http://www.seer.ufu.br/index.php/dominiosdelinguagem/article/view/11401/6686. Acesso em: 22 abr. 2021.

DAYRELL, C. O uso de corpora para o estudo da tradução: objetivos e pressupostos. Tradução em Revista, Rio de Janeiro, v. 2, p. 87-102, 2005. Disponível em: https://www.maxwell.vrac.puc-rio.br/25346/25346.PDFXXvmi=. Acesso em: 22 abr. 2021.

FROMM, G. O uso de corpora na análise linguística. Revista Factus, São Paulo, v. 1, n. 1 1, $\quad$ p. 69-76, 2003. Disponível https://comet.fflch.usp.br/sites/comet.fflch.usp.br/files/u30/fromm_corpora.pdf. Acesso em: 30 jun. 2021.

MARTINS, S. C. Proposta de uma base de conhecimento multilíngue on-line de expressões cromáticas da Fauna e da Flora. 2017. 429 f. Tese (Doutorado em Estudos Linguísticos) - Instituto de Biociências, Letras e Ciências Exatas, Universidade Estadual Paulista Júlio de Mesquita Filho, São José do Rio Preto. Disponível em: https://repositorio.unesp.br/bitstream/handle/11449/148762/martins_sc_dr_sjrp.pdf?seque nce=3\&isAllowed=y. Acesso em: 23 abr. 2021.

MELO, P. A. G. O léxico toponímico: nomes de motivações de natureza antropocultural na toponímia de Alagoas. Nonada: Letras em Revista, Porto Alegre, v. 1, p. 244-261, maio. 
FROMM, G.; SANTOS, C.G.

2017. Disponível em: https://www.redalyc.org/articulo.oa?id=512454262016. Acesso em: 23 abr. 2021.

MICHAELIS. Dicionário Brasileiro da Língua Portuguesa. [S.I.]: Melhoramentos, 2015. Disponível em: https://michaelis.uol.com.br/. Acesso em: 23 abr. 2021.

PAULA, M. H. D.; ALMEIDA, M. A. R. D.; REZENDE, A. D. M. Língua, cultura e léxico: confluências entre Lexicografia e Filologia. Entretextos, Londrina, v. 16, p. 7-27, jul./dez 2016. Disponível em: http://www.uel.br/revistas/uel/index.php/entretextos/article/view/16564. Acesso em: 7 maio 2021.

REZENDE, G. J. Os Diários Impressos em Minas Gerais. In: ENCONTRO NACIONAL DE HISTÓRIA DA MÍDIA UNICENTRO, 8., 2011, Guarapuava. Anais... Guarapuava: Unicentro. Disponível em: http://www.ufrgs.br/alcar/encontros-nacionais-1/encontrosnacionais/8o-encontro-2011

1/artigos/Os\%20Diarios\%20Impressos\%20de\%20Minas\%20Gerais.pdf/view. Acesso em: 23 abr. 2021.

SANTOS, C. G. A importância do corpus em atividades sobre neologismos. In: Simpósio Internacional de Ensino da Língua Portuguesa, 6., 2016, Uberlândia. Anais [...]. Uberlândia: $\quad$ EDUFU, 2016. p. 199-208. Disponível em: http://www.ileel.ufu.br/anaisdosielp/arquivos/anais_sielp_2016.pdf. Acesso em:

SANTOS, C. G. A criatividade nas denominações de operações policiais: um estudo preliminar de campos semânticos a partir de um corpus de jornais mineiros. 2017. $113 \mathrm{f}$. Dissertação (Mestrado em Estudos Linguísticos) - Programa de Pós-Graduação em Estudos Linguísticos, Universidade Federal de Uberlândia, Uberlândia, 2017. Disponível em: https://repositorio.ufu.br/bitstream/123456789/20924/1/CriatividadeDenominacoesOperacoes. pdf. Acesso em: 30 jun. 2021.

SCOTT, M. WordSmith Tools version 6. Liverpool: Lexical Analysis Software, 2012.

SEABRA, M. C. T. C. D. Referência e Onomástica. In: MAGALHÃES, J. S. D.; TRAVAGLIA, L. C. Múltiplas perspectivas em Linguística. Uberlândia: EDUFU, v. 1, 2006. p. 1953-1960.

TEIXEIRA, E. D. A Linguística de Corpus a serviço do tradutor: proposta de um dicionário de culinária voltado para a produção textual. 2008. 400 f. Tese (Doutorado em Estudos Linguísticos e Literários em Inglês) - Faculdade de Filosofia, Letras e Ciências Humanas, Universidade de São Paulo, São Paulo. Disponível em: https://www.teses.usp.br/teses/disponiveis/8/8147/tde-16022009-

141747/publico/TESE_ELISA_DUARTE_TEIXEIRA.pdf. Acesso em: 24 set. 2020.

ZAMARIANO, M. Reflexões sobre a questão do nomepróprio na Toponímia. Cadernos de Letras da UFF, Rio de Janeiro, v. 1, p. 351-372, 2012. Disponível em: http://www.cadernosdeletras.uff.br/joomla/images/stories/edicoes/45/diversa5.pdf. Acesso em: 23 abr. 2021.

ZAVAGLIA, A. et al. Terminologia e Tradução: o caso dos textos literários. In: ALVES, I. M., et al. Estudos lexicais em diferentes perspectivas. São Paulo: FFLCH/USP, v. 2, 2010. p. 17-34. 
FROMM, G.; SANTOS, C.G.

\section{Como citar este artigo (ABNT)}

FROMM, G.; SANTOS, C.G. Descrição do léxico por meio de nomes de operações policiais a partir de um corpus de notícias. Revista do SELL, Uberaba, MG, v. 10, n. 01, p. 56-75, 2021. Disponível em: <inserir link de acesso>. Acesso em: inserir dia, mês e ano de acesso. DOI: inserir link do DOI.

Como citar este artigo (APA)

Fromm, G. \& Santos, C.G. (2021). Descrição do léxico por meio de nomes de operações policiais a partir de um corpus de notícias. Revista do SELL, 10 (1), 56-75. DOI: inserir llink completo de acesso ao DOI. 